2020-05-01

Representing the Planet: Affect, Scale and Utopia

Sergeant, David

http://hdl.handle.net/10026.1/12724

10.1215/00295132-8139267

Novel: A Forum on Fiction

Duke University Press

All content in PEARL is protected by copyright law. Author manuscripts are made available in accordance with publisher policies. Please cite only the published version using the details provided on the item record or document. In the absence of an open licence (e.g. Creative Commons), permissions for further reuse of content should be sought from the publisher or author. 


\section{REPRESENTING THE PLANET: AFFECT, SCALE AND UTOPIA}

How to do justice to the interconnectedness of the world without tipping into an oppressive uniformity? How to admit both unity and difference? These questions go to the heart of planetarity, the 'critical-theoretical model' which has recently been proposed as a successor to the 'totalizing paradigm of modern-age globalization' (Elias and Moraru xi). Both discourses are governed by the relationship between the maximal scale of the world and the subsidiary scalar levels which constitute it: however, if in globalization those subsidiary levels are envisioned as converging on a homogenous and hierarchical whole, in planetarity the aim is to maintain them in a dialogic relationality that can better sustain difference and dispersal. On the face of it, such a recalibration of the scalar framework seems relatively straightforward, with the challenge then being to translate this new model into adequate vocabularies, cartographies, stylistics, hermeneutics and 'theories of value' (Elias and Moraru xxvi). However, the three novels discussed in this essay suggest that, in the realm of narrative at least, the retention of the maximal scale as a constituting frame for representation, however informed by a salutary sense of urgency with regard to our world situation, risks forestalling any attempt to move beyond the paradigms of globalization.

In both Doris Lessing's The Four-Gated City (1969) and Ben Lerner's 10:04 (2015) the relationship between parts and whole takes shape via the medium of affect, as the protagonists intuit the living reality of a human collective that is, in its size and scope, potentially commensurate with the maximal scale of the world. In this sense, the scalar tension underlying both planetarity and globalization becomes supercharged in these texts: as the defining characteristic of the part becomes a desire for the whole that is seemingly destined to diminish or extinguish it. The result of this paradoxical dynamic is that both novels turn to a large-scale formal modelling in which individual and collective can 
supposedly blend without either suffering reduction - a representational manoeuvre which is also characteristic of many discussions of planetarity, as well as its 'lexical-methodological cognates' (Moraru 45) in fields such as ecocriticism and world literature. ${ }^{1}$ This approach is then contrasted with Kim Stanley Robinson's Aurora (2015), in which the possibility of representing the maximal scale of the collective is self-consciously repudiated: a decision linked to the narrator's prioritisation of linear narrative over the kinds of formal modelling seen in the other texts.

This point of difference allows the periodization entailed by the planetary turn to be opened up to a reciprocal exchange with the work of perhaps the pre-eminent contemporary theorist of periodization, Fredric Jameson; an opening enabled by the chronological and generic range of the three texts under discussion. While Jameson's work has not been lacking from accounts of the planetary, it has generally registered there only as a descriptor of a globalizing postmodernism which is now being superseded. Robinson's novel, however, suggests that the scalar reconciliation of parts and whole which is desired by planetarity might equate to Jameson's account of utopia, as it arises from a broader span of literary history. In trying to do full representational justice to the maximal scale, both The FourGated City and 10:04, as well as the planetary discourses they resemble, end up with a predominantly spatial narrative that risks inadvertently returning us to the historically neutered, globalizing postmodernism which Jameson famously characterised as dominated by 'categories of space' (1992: 16). What is needed is a recovery of 'the great high modernist thematics of time and temporality', and their utopian orientation towards the future: something that Aurora achieves by deserting the maximal scale to prioritise narrative. However, in one important respect Aurora also suggests how Jameson's work might be opened up, in turn, to the discourse of planetarity: as it identifies the biosphere as a realm in which the challenges of affect and scale are reconciled. 
DORIS LESSING: NEW WORLD, NEW AFFECT

The Golden Notebook (1962) remains Doris Lessing's most famous work in part for breaking with the realism that had dominated her career until that point. However, in retrospect, the novel's experimentalism can be seen as the first - and false - step in a journey of reinvention whose ultimate destination was science fiction, the genre which would dominate her output through the 1970s and early 1980s. The key reason for this has also been missed: that The Golden Notebook's struggle to find a fictional form appropriate to its contemporary moment is coincident with the frustration of wanting to realise an affectual state that can be sensed, and which seems new, but which Lessing and her protagonist ciphers repeatedly fail to adequately render. $^{2}$ The impasse is encapsulated by Anna Wulf countering her psychoanalyst's claim that "The details [of women's lives] change, but the form is the same",, with the flat assertion of a new affectual reality instigated by an equally new historical moment, figured in this case by the bad global figure of the Bomb: “They didn't feel as I do ... I don't want to be told when I wake up, terrified by a dream of total annihilation, because of the H-bomb exploding, that people felt that way about the cross-bow. It isn't true. There is something new in the world"' (415). It is this discussion that leads to Anna's more well-known claim that "It's a question of form"” (417). This exchange could stand as a summary of The Golden Notebook, where the failure to find an adequate form for the new affect is compounded by the mistaken attempt to sustain it through romantic relationships, a mistake repeated by the return-to-realism novel that followed, Landlocked (1965). 
It is this new affect that prompts both Lessing's initial switch away from realism in The Golden Notebook, and then the successive switch away from that novel's experimentalism in Landlocked and The Four-Gated City (1969). However, to understand why Lessing finally settles on science-fiction in the latter novel it is first necessary to explain why it appears there only as a short 'Appendix', with most of the novel's six hundred plus pages being given over instead to a broadly realist narration of Martha Quest's progress through '50s and '60s London. The answer lies in the new and scarcely communicable affect which punctures the narrative: 'a quiet space and ... wave-length' (40), 'the sense of me, nameless, recognizable only to me' (245). These breakthroughs are concerned with Martha's identity; however, they also become increasingly collective, the sensed 'wave-length' a site where individual and group can telepathically merge, in a way that might potentially include all of humankind. As such this new affect, manifested in the individual, becomes commensurate with the maximal scale of the world: and it is in this attempt to reconcile the level of individual difference with that of global oneness that Lessing's work speaks to the discourse of planetarity, despite its largely anthropocentric focus setting it at a remove from the latter's 'eco-logical' (xxiii) openness to the nonhuman. It is this scalar ambition which also prompts the turn to science fiction at the very end of the novel, as a genre that can more fully realise it. Thus, the Appendix sees the birth, after a nuclear holocaust, of a new generation of humans who will inherit the world, united by their embodied experience of their perfect collectivity: by 'nothing you can measure or count, but [they] all feel it' (660). This evolutionary solution to the intertwined problem of scale and affect is also seen in other seminal examples of twentieth century science fiction: for instance, Arthur. C. Clarke's Childhood's End (1953), and Greg Bear's Blood Music (1985) and Darwin's Radio (1999).

However, it is not so much science fiction's capacity for such fantastic invention that prompts Lessing's turn to it, as its amenability to a large scale formal modelling that can 
succeed narrative's inability to portray an affect experienced by individuals that is also, at one at the same time, collective. For instance, a telepathically sustained union might be the telos of Martha's new 'sense' in The Four-Gated City, but on reaching that point it is no longer composed of affect-rich individuals, but a spatialized blueprint: people as nodes in a distributed network. Similarly, Martha shares a house with an estranged couple, Mark and Linda, who increasingly become extensions of her personality and history: Mark a version of her past, undermined by an egotistical emotional chaos; Linda a cipher for her extrasensory, intuitive future. As this collective structure takes shape, however, it becomes increasingly less subjective and experiential as it is mapped to the house as physical structure: Mark in his study, the place of the rational mind, and Linda in the basement, the realm below, with Martha moving between them. The very strategies which are supposed to scale the affect up, also risk evaporating it. The importance of this transfer from individually experienced affect to structure is reflected by the fact that its premier example gives The Four-Gated City its title, via a fabular novella written by one of the characters. This 'parable' or 'blueprint' describes a city blending part and whole through a geometrically harmonious spatiality - the gates at the four compass points, the roads forming 'a web of arcs intersected by streets running in to a centre' $(151)$ - that both mirrors and expresses the city's social holism: '[e]very person in the city had a function and a place; but there was nothing static about this society: people could move out and up and into other functions, if they wished to' (151).

This becomes a common pattern in Lessing's novels of the 1970s: a realist or pseudorealist narrative, focused on the psychology and affective lives of individuals, either culminates in a spatialized model designed to express a greater unity, or carries briefer, emblematic examples of such models embedded within it. An example of the former is The Making of the Representative of Planet 8 (1982), in which the verisimilar account of surviving a planet's descent into an ice-age ends with the protagonist's death into a cosmic 
unity figured by the 'intricate structures and shapes' made by 'patterns of matter' (157-8); while an example of the latter are the geometric cities and the jewelry-like 'Signature' which crop up throughout Shikasta (1979). In all these works a reconciliation with the maximal scale is not just apprehended intellectually but sensed, such that it gains an urgency and undeniable force. However, to represent the supposed transfer of this affect into a supraindividual entity, the narrative must turn away from the individual and embodied and to a relatively affect-less formal structure.

10:04 AS COLLECTIVE BODY

Ben Lerner's 10:04 follows a first-person narrator - some of whose biography and writings overlap with Lerner's - through his life in New York City and elsewhere, as he contemplates starting a family with his best friend and confronts the paradoxes and problems of the way we live now in the First World. In the explicitness with which 10:04 addresses such issues it might seem strikingly contemporary; however, in its interlinked treatment of affect and scale the novel closely resembles Doris Lessing's fiction from the 1970s. This similarity has the potential to complicate the periodizing implied by recent accounts of a planetary 'turn'; not least because the similarity can also be seen as extending to those accounts themselves.

Even more explicitly than The Golden Notebook and The Four-Gated City, 10:04 is concerned with a new form of affect, the lived experience of a human collective; and while that is generally identified with the city in Lerner's novel, in its massive supra-individuality it is equivalent with the points of maximal scale that also govern Lessing's work and discourses of planetarity: 
Overhead the stars occluded by light pollution were presences like words projected through time and I was aware that water surrounded the city, and that the water moved; I was aware of the delicacy of the bridges and tunnels spanning it, and of the traffic through those arteries, as though some cortical reorganization now allowed me to take the infrastructure personally, a proprioceptive flicker in advance of the communal body. (28)

What is being sensed exists in tension with its hypothetical nature: the narrator might be briefly 'aware' of the communal, but the construction both trades on and is vulnerable to the fact that this communality is no more than his own singular fiction. The 'as though' is crucial, allowing an intellectual awareness of water and infrastructure such as any person might possess - the knowledge, for instance, that traffic will be passing through tunnels - to elide into an embodied experience of the same, which if shared by everyone would entail the metaphorical 'communal body' of a city's infrastructure becoming actual. This elision is aided by the narrator's characteristically multivalent language: by the moving water and the 'delicacy' of the bridges already possessing qualities (movement, touch) that draw on embodied cognition; while the roads as 'arteries' and the taking of something personally entail a more transparent conversion into the bodily and emotive. Such embodied apprehension teeters in 10:04 always on the edge of possibility, the physical immediacy ('I was aware') giving the sense of a present actuality, while the language and metaphoric mode ('as though') fend it off as fiction.

This positing of a new affect of the collective is accompanied by a formal or figural representation of it, also familiar to us from Lessing. 10:04 repeatedly locates models in which the one entity is, simultaneously and inextricably, plural. An example is the narrator's encounter with Christian Marclay's film The Clock (2010), a collage of clips from other films synched to the 24-hour period in which it is shown: 
As I made and unmade a variety of overlapping narratives out of its found footage, I felt acutely how many different days could be built out of a day, felt more possibility than determinism, the utopian glimmer of fiction. (54)

The artwork becomes the utopian 'communal body' because it is both multiple and singular: more explicitly though no differently than other works of art, it accommodates multiple interpretations while remaining one entity. Similarly, the narrator glosses a poem made up of parts of other poems as 'a kind of palimpsestic plagiarism that moves through bodies and time, a collective song with no single origin, or whose origin has been erased' (114). A slightly different structural modelling occurs when the narrator talks of how 'the transpersonality of prosody constituted a community' (113). Rather than the one artwork also being plural, via interpretations and/or intertexts, here the medium acts more like a networking umbilical cord strung between individuals, making them one: not unlike the 'infrastructure' sensed earlier, or Lessing's telepathic network. Such a merging of the sensed and structural is also evident when the narrator considers inappropriate jokes:

... bad forms of collectivity that can serve as figures of its real possibility: prosody and grammar as the stuff out of which we build a social world, a way of organizing meaning and time that belongs to nobody in particular but courses through us all. (116)

Such 'figures' are spatialized models which reconcile the scalar extremes of individual and collective; though the sanguine register of 'courses' confirms how these are merged in 10:04 with affect and the language of the body, as much as the language of architecture or construction. Indeed, the importance of the part/whole model lurks even within the narrator's 
favourite bodily term, the 'proprioceptive', the sense of the movement and position of a body's parts: which is to say, the whole perceiving the separate yet inseparable elements which make it up.

However, when 10:04 tries to bring affect and formal figure together in the material world the potential weaknesses in this narrative strategy become clear; as when the narrator views the Manhattan skyline:

It was a thrill that only built space produced in me, never the natural world, and only when there was an incommensurability of scale - the human dimension of the windows tiny from such distance combining but not dissolving into the larger architecture of the skyline that was the expression, the material signature, of a collective person who didn't yet exist, a still-uninhabited second person plural to whom all the arts, even in their most intimate registers, were nevertheless addressed. ... What I felt when I tried to take in the skyline and instead was taken in by it - was a fullness indistinguishable from being emptied, my personality dissolving into a personhood so abstract that every atom belonging to me as good as belonged to Noor, the fiction of the world rearranging itself around her. (108-9)

As the windows are to the city, so the individuals are to the collective: the analogous structure again does the work of synthesising difference and unity. However, while windows are easy to combine in this way, they come with humans who look out of them who are not, or at least, will not be if the analogy is pursued much further; and though, here as elsewhere, the narrator dutifully recognises the fictionality of the comparison ('didn't yet exist'), the scalar problems that are built into the actually existent world risk exposing his new collective affect ('[w]hat I felt when') as an empty lyricism, in a way that palimpestic poems and films do not thanks to their immaterial virtuality. In this respect 10:04 encapsulates a problem that 
attaches to affect theory more widely. The appeal of affect in many theorisations of it is the same as it is for Lerner and Lessing: when modelled as pre-subjective intensities, affects can act as a scalar solution, simultaneously one and many both in themselves - in that they are indistinguishably the same in their pre-representational nature, but are apparently experienced as different - and in their distribution in, between and beyond individual subjects. This underlies the potentially transformative role they are described as having in the work of critics such as Brian Massumi, Michael Hardt and Antonio Negri, John Protevi and Heather Houser. However, as Amy J. Elias has noted of Hardt and Negri, such theories 'don't answer the question of how human nature can be transmuted and what might be the nature of the new social institutions that alter it' (53). In converting affect into emotion - which is to say, in representing it, and making it available to narrative and history - its scalar fluency is inevitably lost, and the question remains as to what might medium take such feelings forward, into a different kind of future and up the chain of scale. ${ }^{3}$

This exposure to the intractable scalar nature of reality is why Lerner so often turns to the art-work or medium as a formal model, as in the extract above, which quickly works its way back to 'fiction' - it is his equivalent of Lessing's turn to science fiction. Like fabular cities and telepathic children, poems and films serve as malleable forms which might model a collectivity that can supposedly sustain the individuality in which the original, affect-full experience of the collective was manifested. Hence the passage above moving quickly onto 'fiction' at its end; and hence the emergence, at the novel's conclusion, of 10:04 itself as the ultimate figure for the 'collective person':

I will begin to remember our walk in the third person, as if I'd seen it from the Manhattan Bridge, but, at the time of writing, as I lean against the chain-link fence intended to stop 
jumpers, I am looking back at the totaled city in the second person plural. I know it's hard to understand / I am with you, and I know how it is. (240)

It claims to unite different tenses that might in turn unite different viewpoints, of author and individual readers; to unite past and future; to unite itself and the Whitman who it quotes, varying the original slightly, with the unvocalisable change from line break to virgule also exemplifying the novel's epigraph from Walter Benjamin, about the world to come being the same and different to the present world; to unite the prospect of social totality with the language of capitalism ('totaled' refers to damaged art whose value has been paid out by insurance companies); and by merging all these forms of separateness and difference, through the one/many figure of the novel itself, to provide an affect-rich representation of the 'totaled' community. 10:04's modelling of itself recalls the scale bridging city that was fictional avatar of Lessing's novel; the key difference being that while The Four-Gated City acknowledges the non-existent nature of the ideal collective through a blatantly abrupt switch in genre, Lerner sublimates it into the realist world of his novel by using art as a kind of science fiction landscape or technology. ${ }^{4}$ In this sense, the aspiration to do justice to the maximal scale, and the narrative strategies consequent upon that desire, have the potential to cut across more conventional alignments of genre and period: it seems unlikely that many other readings would see Doris Lessing's 1970s science fiction identified with Ben Lerner's intensely self-aware, twenty-first century autofiction. ${ }^{5}$

Notwithstanding their generic difference, what both science fiction and imagined artwork have in common is their amenability to allegory: a similarity which might then explain their resemblance to the aesthetic modes proposed by many discourses of planetarity and its critical cognates, given that Ursula K. Heise has described allegory as a mode that is '[still] hard to avoid in representations of the whole planet' (21). For instance, in outlining a 
new 'organizing principle' for rethinking literary history, Wai Chee Dimock posits genre as possessing the kind of 'fractal geometry' (87) and 'scalar recursiveness' (89) found in nature, in a modelling that solves the scalar challenge of planetarity by suggesting that the micro instance of the individual text reproduces via genre at every level of scale up to that of the world, 'going all the way up and all the way down' (89). This is, of course, a variant of the spatialized, intensively one-and-many model that we have seen in Lerner and Lessing. Similarly, Elias and Christian Moraru speculatively identify a 'relational aesthetic' involving 'interaction, intertextuality, remediation, mash-up, recycling, and quotation' as being 'isomorphic' to the 'geothematics' of planetarity (xxv); Heise proposes 'the infinite zooming capabilities of the internet tool Google Earth' as shifting 'a vision of the global that integrates allegory ... into a more complex formal framework able to accommodate social and cultural multiplicity' (21); and Christian Moraru identifies 'the thematization of the dialectic of micro and macro world pictures' in the 'mix of zoom-in and zoom-out scenes' in Orhan Pamuk's Snow (2002), as well as in a single game of cricket in Joseph O'Neill's Netherland (2009), the decipherment of which allows one to make 'sense of the planet' $(231,229,234)$. In each case the desire to do justice to both macro and micro, unity and plurality, leads to the positing of a structure in which the affect-rich individual instance maps without diminishment to the maximal, unifying structure of the world. As Lessing's and Lerner's novels each suggest, however, the playing out of such a model in narrative seems to risk a transition away from the individual and particular, into the realm of the 'virtual', the 'parable', the 'blueprint'. And as we will now see, this transition is itself a symptom of a wider problem, whereby the attempt to remain keyed to the maximal scale evaporates the realm of history in which those individuals might have acted. 
Kim Stanley Robinson's science fiction novel Aurora sets itself similar challenges to the work of Lessing and Lerner. The novel follows a generation spaceship that has set off to colonize another planet, but which has to journey back to earth, after one hundred and sixty years of travel, when this project proves to be folly. In the second chapter the Artificial Intelligence spaceship is unveiled as the novel's new narrator: it has been instructed to 'make a narrative account of the trip that includes all important particulars' (italics in original). The ship's very first narrative attempt encapsulates the challenge, in its banal enumeration of the ship's population: 'Two thousand, one hundred twenty-two people are living in a multigenerational starship, headed for Tau Ceti, 11.9 light-years from Earth' (45-6). It must represent both the totality described by the number and the individual 'people' who constitute it: the task that was also faced by Lessing's protagonists and Lerner's narrator, and which parallels the scalar challenge structuring planetarity. However, the ship's approach to the task is very different to all of these.

In Aurora the ship confirms how, for any 'account' which sets out to operate under the sign of the world, individual affect will emerge as a linked question and demand; however, it rejects any aspiration to reconcile the two scalar levels. For instance, a reflection on how '[a] narrative account focuses on representable individuals, which creates the problem of misrepresentation by way of the particular overshadowing the general', and of the consequential need to 'register somehow the group itself as protagonist [and] their infrastructure, to the extent that it is significant' (84), leads into a highly technical and statistical account of the humans and their environment. Which is to say, the ship comically demonstrates the impossibility of providing an affect of the maximum scale, of the 'general' and 'infrastructure'. In trying to represent the living existence of the collective, the ship 
simply falls back on routine fictional strategies: a succession of brief, omniscient accounts of what various individuals and small groups are thinking and feeling, supplemented by a succession of instances of what they are saying. Of course, this involves an immediate falling away from the synchronous group which was the object of representation; the hope is that by covering more such 'parts' a sense of the collective's scope and nature is nevertheless enhanced.

This abandonment of the prospect of merging the micro level of affect with the maximal level of the collective also means there is no attempt in Aurora to construct a formal model of the whole. The mimetic urge, which the challenge of planetary scale so often seems to prompt, is replaced by the urge to narrative - and in this regard the crucial change was built into the novel from the start: 'make a narrative account ...'. Time regains priority over space:

How to decide how to sequence information in a narrative account? Many elements in a complex situation are simultaneously relevant. An unsolvable problem: sentences linear, reality synchronous. Both however are temporal. Take one thing at a time, one after the next. Devise a prioritizing algorithm, if possible. (47)

The ship might more accurately - if more laboriously - have said that while time and space are inextricably connected in both reality and language, in the latter the temporal is dominant. As Richard Walsh has observed, readers seeking to understand a fictional text will draw on both narrative (i.e. temporal) cognition 'predicated upon the serial logic of temporal sequence', and spatial cognition predicated 'upon the systemic logic of the spatial field' (474) - though given the nature of narrative the former will always be dominant. Lerner and Lessing try to boost the junior partner in this relationship so as to approximate the 
instantaneous synchronicity of the complex whole. However, the price of this is often a sundering of that whole from narrative, and thereby from history. Given this, it is no surprise that Lessing's work leading up to The Golden Notebook reflects her increasing disillusionment with political activism, which in The Four-Gated City finds its replacement in a comparatively apolitical mysticism; while in 10:04 there is little attempt to imagine how a better collective might actually be realised in the world, with the result that its wistfully posited models could fit a dystopian outcome as easily as a utopian one - something that also could be said, indeed, of affect in many theorizations of it, where it resembles a shadowy vitalist aquifer capable of taking good or bad form depending on how it is tapped. ${ }^{6}$ In Robinson, in contrast, the necessary questions of social and economic justice, political action, and so on, are made the subject of the plot, articulated through characters using the 'high protagonicity' (54-5) of narrative: the realm of individual affect and action which The FourGated City and 10:04, in their different ways, slid away from.

The work of Fredric Jameson - Robinson's PhD supervisor and a figure whose work has entertained a close reciprocal relationship with his fiction ${ }^{7}-$ can both clarify what is at stake here, and allow us to graft these differing approaches to a wider literary history. Jameson famously identified the postmodern turn with a 'waning of affect', characterised by 'the high, the intensity, exhilaration, euphoria ...' (2007: 234-5); in which 'the great high modernist thematics of time and temporality' are replaced by 'categories of space' (1992: 16). The novels of Lerner and Lessing can be seen as striving to supplant this inane affect with a more meaningful and positive affect of the collective: indeed, given the intoxicated register of Jameson's description, it is striking that advances in consciousness in The FourGated City are explicitly distinguished from drug-use, while in 10:04 the narrator distances himself from the solipsism of drug-taking. The scale-resolving models of Lerner and Lessing might then occupy the same position as Jameson's 'utopian impulse' in Archaeologies of the 
Future (2005): positive transformations of a spatialized postmodernity, in which 'the subject or ego - a historical result of the development of commerce and capitalism - is again dissolved in its monadic isolation and returned to its ground as a nexus for human relationships and a transmission point for collective relationships' (2005: 300).

However, Jameson's account is crucially qualified by the assertion that all such utopian representations are doomed to failure - 'the radical difference of the new Utopian society makes it impossible to imagine' (2005: 86) - though this failure might be necessary to catalyse change. The evolution of high modernist affect into utopian impulse in Jameson's account suggests why this might be: the former's concern with 'time and temporality' disallows a replacement of the postmodern with an spatialized equivalent that, however utopian, would prevent any movement towards its realisation for its spatiality annulling such time. A reinjection of narrative is needed - and hence the emphasis on the utopian impulse in Archaeologies of the Future, rather than utopia as an endpoint; as well as the ship-narrator's acceptance in Aurora of both the inevitable temporality of narrative, and the equally inevitable failure to completely represent the full reality of the whole - the collective and its infrastructure - which is its subject. The affective urge that we saw in The Four-Gated City and 10:04 might be a driver for change, but as soon as the maximal scale which generated it becomes the goal of representation it cancels its own becoming: as was confirmed by the transformation of the affective impulse into spatialized figures which, in their anaesthetising of narrative, also excise the historical and narrative time that would be needed to bring them about. As we have seen, this diagnosis might equally apply to many theorizations of planetarity. The attempt to replace the globalized homogeneity of postmodernity with a more dynamic relationality might produce a more ethical model of the relationship between maximal and subsidiary scales, that symbiosis which governs our historical moment; 
however, the aesthetics that results from such a modelling risks producing only a variation on the same old stasis or deadlock.

\section{THE BIOSPHERE: PLANETARITY MEETS UTOPIA}

In deserting any ambition to comprehensively represent the maximal scale, Aurora might evade the pitfalls which Lessing and Lerner both encounter; but what stops this desertion from becoming a problem on its own account, an outright evasion of the challenge of scale which characterises the contemporary? Or to put it another way, how does Aurora acknowledge our inescapable tethering to the maximal scale of the world?

As it happens, Robinson's novel does at one point turn to the kind of modelling that we saw in The Four-Gated City and 10:04: as the ship, nearing its demise, breaks from a consideration of how its (now reduced) '641 people' have been 'brought back home', to an attempt to render the actuality of this collective existence:

Maypole weaving to celebrate the spring. Ribbons danced into a woven pattern judged pleasing to the eye. The pole a symbol of the axis mundi, the world tree. We danced that dance. (387)

It is a spatialized model of the collective, charged with embodiment and emotion, and with no falling away into the 'information loss' (232) of narrative that the ship elsewhere accepts. However, it is telling that this passage occurs at the very moment the ship is leaving the realm of action and existence and action (as well as narrative); and its anomalous nature is highlighted by the paragraph being separated by section breaks from the rest of the text. 
Furthermore, while the passage appears at the climax of the ship's narration, it is nowhere near the climax of the novel as a whole; and instead we are returned to a conventional third person narration to follow the main protagonist, Freya, as she becomes embroiled in the politics of earth: the kind of nationalistic and factional squabbling that is our current approximation of a global collective. In other words, the novel seems to risk veering into a different kind of stagnation: a helplessly faithful transcription of political impotence, stupidity and futility, with no seeming way out, of the sort that had caused Lessing to grow frustrated with realism in the early 1960s. But where Lessing eventually responded with the spatialized modellings allowed by science fiction, as we have seen, Aurora's ultimate response is to immerse Freya in her own bodily affect, as she discovers the experiential pleasures of beaches and coasts, which she has never encountered before; and the final thirty pages of the novel are made up in large part of the pleasures of tumbling in the surf and being naked in the sun.

What stops this being an escapist withdrawal into individuality, the ultimate desertion of the planetary scale of our times? The answer is that Freya's affect is potentially universal, in that the feel of sea and sun is much the same for all humans: and we see the apparent truth of this as she has to be guided in enjoying them by another person, such that their intensely individual experience translates fluently into her own. Aurora thus traces a curious path. The planet as ship/narrator has to desert many of the properties of the maximal scale in order to undertake narration: focusing on seriality and individuality at the expense of the synchronicity and plurality which is its full existence. However, at the very end of the novel an individual gains access to that maximum framing scale through the addition of environmentally generated affect. Phenomenological immersion in the biosphere, through and in which our generic individuality is articulated, solves the twin problems of scale and affect: it is the lived equivalent of 10:04's 'prosody and grammar', the stuff that really does 
'[belong] to nobody in particular but courses through us all'. Furthermore, Freya's experiences on the shore will be part of a collective project to reconstruct beach habitats following a catastrophic rise in sea levels: they are thereby harnessed to narrative and history in a way that distinguishes them from the simplistic versions of Romantic organicism and the absolute which were influential in the first wave of ecocriticism. As the plot of Aurora recognises, under an ongoing regime of worldwide environmental destruction, individual experience of the biosphere becomes both political and historical; as well as an 'object of desire' (2005: 226) of the sort that Jameson identified as essential to utopia.

In this addition of the nonhuman to the maximal scale - of the 'biophysical' to the 'cultural' collective (xxiii) - Aurora might be seen as having moved closer to a planetary mode than did The Four-Gated City and 10:04, with their predominantly human focus. However, Aurora also suggests that much planetary theory risks pointing down a dead end, at least with regard to narrative, if it mistakes the scalar challenge which constitutes our historical moment as a demand to formally reproduce its scope and extent. In The FourGated City and 10:04 the desire to meet this challenge becomes a kind of impossible affect, in a way that reflects both the salutary sense of urgency which a knowledge of our world situation provokes, as well as an impatience with the seeming impotence of that knowledge. However, the two texts also show how the attempt to reconcile the maximal scale with its component levels risks tripping the narrative from time into space; and so out of history, and into a consolatory ideal that is as inert as it is inaccessible. Planetarity's reconfiguration of the world dynamic of globalisation might be better served by transposing the maximal scale from the plane of space onto the axis of time, such that it becomes coincident with utopia as Jameson has described it: a catalytic present absence that might generate 'a narrative account of the trip', or, as Robinson put it in an interview, a 'history that gets us from here to there' (2004: 187). ${ }^{8}$ 
Conversely, the emergence of the biosphere as an already existent utopian dimension in Aurora - a scalar solution, in which individual affect and totalizing system are indistinguishable - points up the strangely muted place that the environment holds in Jameson's 'archaeology of the future'. But what might it mean for every 'future-oriented' impulse - 'from games to patent medicines, from myths to mass entertainment, from iconography to technology, from architecture to eros, from tourism to jokes and the unconscious' $(2005,2)$ - to require some kind of environmental accounting before its utopian measure can be said to be fully taken? That any revolutionary political practice will now require an ecological dimension is a truism, but the equation of utopia with the biosphere returns us with a particular force to the ethical negotiations it entails. If the concept of utopia might allow planetarity a better purchase on narrative and so on history, then, conversely, planetarity can give utopia the ethical and ecological weave which the twenty-first-century world requires of it. The spatiality which implicitly governs issues of the 'bioconnective' and 'relatedness' (Elias and Moraru, xxiv, xxi) joins the temporality of the utopian impulse which would feed them into history; and in this re-soldering of the narrative fundamentals of space and time, the outline of a workable planetary stylistics might be glimpsed.

\section{WORKS CITED}

Dimock, Wai Chee. 'Genre as World System: Epic and Novel on Four Continents.' Narrative 14: 1 (Jan. 2006): 85-101. 
Elias, Amy J. 'The Commons ... and Digital Planetarity.' The Planetary Turn: Relationality and Geoaesthetics in the Twenty-First Century. Ed. Amy J. Elias and Christian Moraru. Evanston, Il.: Northwestern UP, 2015. 37-70.

Elias, Amy J. and Christian Moraru. 'Introduction: The Planetary Condition.' Ed. Amy J. Elias and Christian Moraru. The Planetary Turn: Relationality and Geoaesthetics in the Twenty-First Century. Evanston, Il.: Northwestern UP, 2015. xi-xxxvii.

Figlerowicz, '10:04/10:05'. Marta. Post45. $21 \quad$ Jan. 2015. $<$ http://post45.research.yale.edu/2015/01/10041005/>

Friedman, Susan Stanford. 'Planetarity: Musing Modernist Studies.' Modernism/modernity 17: 3 (Sept., 2010): 471-99.

Gregg, Melissa and Gregory J. Seigworth. 'An Inventory of Shimmers'. The Affect Theory Reader. Ed. Melissa Gregg and Gregory J. Seigworth. Durham, NC: Duke University Press, 2010. 1-28.

Hardt, Michael and Antonio Negri. Commonwealth. Cambridge, Mass.: Harvard UP, 2009.

Heise, Ursula K. Sense of Place and Sense of Planet: The Environmental Imagination of the Global. Oxford: Oxford UP, 2008.

Houser, Heather. Ecosickness in Contemporary U.S. Fiction: Environment and Affect. New York: Columbia UP, 2014.

Jameson, Fredric. An American Utopia: Dual Power and the Universal Army. Ed. Slavoj Žižek. London: Verso, 2016.

-- Archaeologies of the Future: The Desire Called Utopia and Other Science Fictions. London: Verso, 2005.

-- Postmodernism, or, the Cultural Logic of Late Capitalism. London: Verso, 1992.

-- The Antinomies of Realism. London: Verso, 2013.

-- The Modernist Papers. London: Verso, 2007. 
Katz, Daniel. (2016) "'I did not walk here all the way from prose": Ben Lerner's virtual poetics'. Textual Practice (24 March 2016): 1-23.

Lerner, Ben. 10:04. Granta: London, 2015.

--- 'The Actual World.' Frieze. 16 June 2013. <https://frieze.com/article/actual-world> Lessing, Doris. Shikasta. 1979. London: Grafton Books, 1981.

--- The Four-Gated City. 1969. London: Paladin, 1990.

--- The Golden Notebook. 1969. London: Flamingo, 1993.

--- The Making of the Representative for Planet 8. 1982. London: Granada Publishing, 1983.

Leys, Ruth. 'The Turn to Affect: A Critique'. Critical Inquiry 37: 3 (Spring 2011): 434-472

Massumi, Brian. Parables for the Virtual: Movement, Affect, Sensation. Durham: Duke UP, 2002.

McVicker, Jeanette. 'Thinking with the Planet: a Review of The Planetary Turn: Relationality and Geoaesthetics in the Twenty-First Century.' electronic book review. 11 June 2016. <http://www.electronicbookreview.com/thread/criticalecologies/eco-logic> Moraru, Christian. Reading for the Planet: Toward a Geomethodology. Ann Arbor: University of Michigan Press, 2015.

Protevi, John. Political Affect: Connecting the Social and the Somatic. Minneapolis : University of Minnesota Press, 2009.

Robinson, Kim Stanley. Aurora. London: Orbit, 2015.

-- 'Ecotopia and the 1970s Utopian Moment.' Utopian Dreaming: 50 years of Imagined Futures in California and at UCSC, University of California, Santa Cruz. 6 Nov. 2015. $<$ https://www.youtube.com/watch?v=rsSfbS6inko $>$

Robinson, Kim Stanley, Imre Szeman and Maria Whiteman. 'Future Politics: An Interview with Kim Stanley Robinson.' Science Fiction Studies 31: 2 (Jul., 2004): 177-188. 
Smith, Rachel Greenwald. 'Postmodernism and the Affective Turn.' Twentieth-Century Literature 57:3 \& 57:4 (Fall/Winter 2011): 423-446.

Spivak, Gayari Chakravorty. 'World Systems \& The Creole.' Narrative 14: 1 (Jan. 2006): 102-112.

Vermeulen, Peter J. Contemporary Literature and the End of the Novel: Creature, Affect, Form. Basingstoke: Palgrave, 2015.

Walsh, Richard. 'Beyond Fictional Worlds: Narrative and Spatial Cognition.' In Emerging Vectors of Narratology, edited by John Pier and Philippe Roussin. Berlin: Walter de Gruyter, 2017. 461-78.

\footnotetext{
${ }^{1}$ For a comprehensive account of the critical discourses upon which planetarity builds, see the introduction by Elias and Moraru; as well as the overviews by Friedman and McVicker. 2 As Rachel Greenwald Smith has noted, 'work on affect in the humanities and social sciences is wildly varied in theoretical antecedents, method, archive, and conclusions' (428). As will become clear, this essay mainly focuses on the formulation of affect that arises out of the Deleuzian vitalist tradition: which, as Peter J. Vermeulen puts it, distinguishes between 'affects [as] non-cognitive and non-representational intensities that take place outside of consciousness, [while] emotions emerge when such intensities are narrativised, named, and represented as part of individual experience' (8). As Smith notes, Brian Massumi’s Parables for the Virtual is often considered the foundational contemporary work here.

${ }^{3}$ Ruth Leys' critique of affect theory gives a complementary description of the essential problem: 'it is not at all clear how one might go about deliberately influencing what in oneself and others is beyond conscious control; the emphasis on the importance of the subliminal visceral register in people's responses makes it difficult to imagine how a political activist might intervene strategically in a particular situation' (451 n.48).
} 
${ }^{4}$ In an article on the appeal of the "virtual' Lerner defines " science fiction"” as "[f]iction that describes encounters with artificial objects that don't yet or can't yet exist ... that attempts to make discernable the shape of an unrealizable technological culture', before proposing 'a genre of "speculative fiction" around virtual arts: Keatsian music; a painting that never dries" (2013).

5 10:04 has been received as an example of the autobiographical turn in recent cultural production, and as part of a largely US postmodern and/or post-postmodern 'literary' tradition: for which see Figlerowicz and Katz respectively.

${ }^{6}$ See for instance Melissa Gregg and Gregory J. Seigworth's introduction to The Affect Theory Reader: '[a]s much as we sometimes might want to believe that affect is highly invested in us and with somehow magically providing for a better tomorrow ... affect instead bears an intense and thoroughly immanent neutrality' (10).

7 Jameson's 2000 essay on The Mars Trilogy is included in Archaeologies, and Robinson's fiction is a point of reference throughout that volume; The Antinomies of Realism (2013) is dedicated to Robinson. An extract from Robinson's most recent novel, New York 2140 (2017), first appeared as a chapter in Jameson's An American Utopia; an extract from which is used as an epigraph in the published novel. Jameson is among those thanked in the acknowledgements to New York 2140 and 2312 (2012), and Robinson often mentions his work in interviews; see, for instance, n.9 below.

${ }^{8}$ Robinson goes on: 'It will be hard (impossible), but in trying, the problem is pointed to (Jameson says this, too)' (187). Gayari Chakravorty Spivak's theorizing of world literature could be seen as working in a similar way, as 'a kind of virtual and inaccessible normativity' (109) that, despite its inaccessibility, might underpin our engagement with texts; it is telling that Spivak also critiques Dimock's isomorphic modelling for prioritising spatialized form over historical time: 'a string quartet and a spider must not be conceptually related because 
they both have eight legs ... people in different historical periods think differently, they inhabit different epistemes' (108). 